\title{
O SUJEITO DE DIREITOS E O CóDIGO CIVIL
}

PROF. RUY CIRNE LIMA ( * )

1. Não há, no art. 2 ${ }^{\circ}$ do Código Civil, uma definição do sujeito da relação jurídica. Declara-se, nessa disposição, que "todo homem é capaz de direitos e obrigações, na ordem civil". Mas, não se exclui, e não poderia excluir-se, que outras entidades, além do homem, hajam de ser, igualmente, capazes de direito e obrigações, na mesma ordem civil.

Antes, o Código, explìcitamente, indica e sublinha a não-coincidência entre o conceito de homem e o de sujeito da relação jurídica. A êste, o Código, ora o denomina, diretamente, sujeito (art. 74 , § único), ora, indivíduo (art. 1597), ora, pessoa (art. 74, II). Toma, a lei civil, essas três designações à filosofia e à teologia. Sujeito, indivíduo e pessoa são expressões que, no discurso filosófico ou teológico, não se adscrevem, tão sòmente, ao homem.

2. Sói dizer-se que o vocábulo técnico, para significar essa entidade essencial à relação jurídica, é a palavra "pessoa". Não coincide, porém, a noção de pessoa, com a de indivíduo, ou a de sujeito de direitos e obrigações. Proclama-se, no art. $4^{\circ}$ do Código, que "a personalidade civil do homem começa do nascimento com vida", embora a lei ponha a salvo, desde a concepcão, os direitos do nascituro. O nascituro não é, pois, pessoa. Entretanto, é ináivíduo, concebido ,por diferenciação dos "indivíduos não concebidos", a que o Código se refere (art. 1718). De outro lado, o in-

(*) Catedrático de Direito Administrativo, Diretor da Faculdade de Direito de Pôrto Alegre, UFRGS. 
divíduo não concebido, ainda que, por igual, se não possa reputar pessoa, pode ser, também, sujeito de direitos, enquanto a direitos sucessórios, desde que caracterizado como "prole eventual de pessoas ... existentes, ao abrir-se a sucessão" (art. 1718). Nem corresponde, enfim, a palavra "pessoa", à noção de sujeito de direitos. Pessoa é, às vêzes, na linguagem do Código, apenas, a figura humana. A "pessoa representada", por obra de estatuária ou retrato (art. 666,X), não é, nessa acepção, e evidentemente, sujeito de direitos.

3. A verdade é que, como tôda a relação, a relação jurídica, ela própria relativiza o que relaciona. Do homem, só importa, à relação jurídica, o que, a essa, lhe concerne e toca. Daí, a alusão a uma aparente pluralidade de pessoas, tendo como suporte um só homem. Assim, "a pessoa do credor ou devedor" (art. 1051), "pessoa da ... família" (art. 1226, VII), pessoa "pertencente ... a um corpo coletivo" (art. 1668). A alusão é, não obstante, inexata.

O contraste, entre essas relativizações do homem e o homem, todo, em tudo o mais de que é, êle, suscetível, exprime de si mesmo, outra relação, e de oposição, - uma relação, em segundo grau, com respeito à relação jurídica, da qual o próprio contraste resulta; uma relação nova, entre a situação, surgida da relação jurídica, e tôdas as demais situações jurídicas possíveis, de que o homem, tcdo, é capaz, diante de todos os demais sujeitos de direitos.

A capacidade de direitos não mais é que essa relação. Tal, o sentido profundo, ínsito no art. $2^{\circ}$ do Código: "todo homem é capaz de direitos e obrigações", já que, pelo nascimento (art. $4^{\circ}$ ), se insere, a criatura humana, desde logo, em uma relação jurídica, a relação de filiação (art. 184; art. 330). Não é, o homem, tão só, capaz dessa relação: pronuncia-se-lhe a capacidade, quanto a direitos e obrigações, segundo a plenitude de sua individualidade, em contraste, precisamente, com a situação jurídica inicial de sua mesma existência, após o nascimento, opondo-o, assim, em tôdas as suas virtualidades, a todos os demais sujeitos de direitos.

4. Não pode haver, realmente, capacidade de direitos, fora da ordem jurídica. Sòmente a entrada na ordem jurídica pode reclamá-la e suscitá-la e, à sua vez, a entrada na ordem jurídica não pode ser, senão a inserção em uma relação jurídica. Pensa-se, não raro, em uma ordem jurídica, anterior ao homem, comum a todo os sêres animados (D. 1, 1, 1, 3), ou no homem, como objeto de direitos (Gai. 1,55). Nada disso. São simultâneas a inserção originária, em uma relação jurídica, e a relativização da criatura humana, da qual procede, por oposição, a capacidade de direitos.
5. A capacidade de direitos, tanto que estabelecida, torna-se, de resto, como relação de segundo gráu, com respeito à relação ju: rídica originária, algo de extrínseco ao homem, em si mesmo. Quanto ao ausente, por exemplo, durante o período da sucessão provisória, a capacidade de direitos se lhe continua como existente, havendo-se, contudo, por extinta, retrospectivamente, desde que provada lhe seja a morte, em data pretérita (art. 479), Se a capacidade de direitos, como é fora de dúvida, se identifica e confunde com o sujeito de direitos, e aquela não mais é que uma relação, ain. da que de segundo gráu, — o sujeito de direitos, pôsto que, do próprio homem, se cuide, é e tem de ser, por fôrça, igualmente, essa mesma relação, ou, seja, uma relação, apenas, por sôbre o homem.

6. Compreende-se, destarte, sem dificuldade, que outros sujeitos de direitos possa haver, além do homem: a par das pessoas naturais (art. 10), as pessoas jurídicas (art. 13). São, as pessoas jurídicas, também, meramente relações. É o que se enuncia no art. 20 do Código: "as pessoas jurídicas têm existência distinta da de seus membros".

7. A forma primitiva da pessoa jurídica é, por certo, a associação ou corporação (D. 3, 4, 1). Essa é, por igual, a figura dominante no elenco das pessoas jurídicas, segundo o Código (art. 16). Relação, associação ou corporação civil subsiste, depois de desaparecidos todos os seus membros, até que inteiramente extintas as responsabilidades sociais, para com terceiros (art. 1407), sem embargo da estipulação da irresponsabilidade dos respectivos mem. bros pelas obrigações sociais (art. 19, IV). De outra parte, prescreve-se, no mesmo Código: “são aplicáveis à partilha entre os sócios as regras da partilha entre herdeiros" (art. 1409). Extintas as obrigações sociais para corn terceiros, desaparecidos todos $\mathrm{CS}$ membros da associação ou corporação, que entidade é essa acêrcà da partilha de cuja sucessão se dispõe? Não pode ser, ela, senão a relação, pela qual se uniram, originàriamente, os membros, da associação ou corporação, a fim de constituirem a pessoa jurídica, a relação que durou e persistiu, como por extrinsecação total, para que, a ninguém, se infligisse dano (D. 1, 1, 10, 1).

8. Essa relação é, mais uma vez, aqui, uma relação de oposição. Não de oposição, entre os sujeitos que a constituiram ou constituem, - o que a parificaria ao "synallagma" (D. 2, 14, 7, 2), mas de oposição dela própria, a todos os sujeitos, nela insertos, e a todos os sujeitos, a ela alheios, - o que a equipara ao mesmo sujeito de direito, como se corpo próprio tivesse ("corpus ... habere") (D. 3, 4, 1). Trata-se de oposição análoga à que informa 
a relação de capacidade de direitos, quanto ao próprio homem. Com respeito a êste, a oposição lhe supõe a individualidade. $\mathrm{Na}$ associação ou corporação, a oposição supõe uma pluralidade; é oposição por transindividualização. A semelhança e a diferença, en tre as duas situações, emergem do paralelismo entre o art. $2^{\circ}$ e o art. 20 do Código. Ali, "todo homem é capaz", e à plenitude, diante de todos os demais sujeitos de direito; aqui, "as pessoas jurídicas têm existência distinta da de seus membros", além de separadas, como sujeitos de direitos, de outros quaisquer sujeitos de direitos.

9. Como relação, o sujeito de direitos destaca-se, dentre tôdas as relações jurídicas, por essa oposição. Sòmente relações jurídicas, com êsse tipo de oposição, podem ser havidas como sujeitos de direitos (D. $3,4,2 ;$ D. $3,4,7,1)$. Sòmente essas podem reputar-se como tendo "existência distinta da de seus membros" (art. 20), ou distinguível da do homem que lhes subjaz. Certo, as fundações, na aparência, fogem aos lindes do conceito, enquanto massas de bens. Na verdade, entretanto, relação jurídica análoga forma a fundação, - relação entre o instituidor e o povo, a benefício do qual a fundação se institui, ou dentre o qual os beneficiários da fundação se individualizarão, segundo a lei (art. 1668, I; art. 1669), ou a vontade privada (art. 24). Às fundações advirta-se, primitivamente se chamou "consortia" (C. 1,2, 23), forma arcáica de administração comunitária (Gai. 3, 154 a, 155 b)

10. Caracterizado, o sujeito de direitos, como relação, e relação de oposição, o intercurso jurídico exige-lhe órgãos, com os quais se supere a mesma oposição que o isola e separa de todos os demais sujeitos de direitos. Quando sujeito de direitos e homem se justapõem, êsse órgão é a vontade individual (art. 85). Quando a justaposicão se não verifica, o órgão é criação da lei, com ou sem dependência dos participantes da relação (art. 17), tendo, como forma atual, no entanto, sempre uma vontade humana, a serviço de outra ou de outras vontades individuais (art. 1395; art. 27).

11. Tôda a oposição, realmente, demanda uma mediação, que a confronte com a unidade. Essa unidade é a unidade dos homens, entre si vinculados, uns aos outros, como por um parentesco, entre consanguíneos (D. $1,1,3$ ), - unidade, a que tendem todos os homens, por uma necessidade vital, a que a ordem jurídica meramente dá expressão (D. 1, 1, 12). A mediação, através da qual se há de atingir essa unidade, é a vontade que se une a outras vontades pelo consenso, - êsse consenso, a que se chama, às vêzes, pacto, porque, segundo os antigos, seria um testemunho de paz $(\mathrm{D} .2,14,1,2)$. Trata-se, verdadeiramente, de mediação. As- sim, "o menor, entre dezesseis e vinte e um anos, não pode para se eximir de uma obrigação (ou, seja, dos efeitos de uma declaração de vontade), invocar a sua idade, se, dolosamente, a ocultou, inquirido pela outra parte, ou, se, no ato de se obrigar, espontâneamente se declarou maior" (art. 155). De outro lado, "cada sócio indenizará a sociedade dos prejuizos, que esta sofrer, por culpa dêle, e não poderá compensá-los com os proveitos que lhe houver granjeado" (art. 1380). Nos dois casos, a mediação nitidamente aparece, acrescentando-se, como um têrmo nôvo, à oposição que se destinava a superar, entre sujeitos de direitos, postos em contacto pelo intercurso jurídico.

12. Ainda no Código Civil Brasileiro, tôda a doutrina do sujeito de direitos denota, de tal sorte, o influxo do pensamento filosófico e teológico, brotado do cristianismo. Como as pessoas divinas, são, os sujeitos de direitos, relações de oposição (Anșelmo, De Processione Spiritus Sancti, 1). Como, entre Deus e os homens, há um mediador (1Tim. 2,5), houveram de ter, também, os sujeitos de direito, análoga mediação, que os reconduzisse à unidade dos homens entre si.

13. Seja, pois, aqui, a palavra final, a lição inicial do excurso, - a lição do grande Bonfante ,resumida, pode äizer-se, apesar de seu alcance genial, a um punhado de linhas impressas: "la teoria della personalità ha il suo addentellato in quei sottili e ingegnosi uomini greci che a un tempo stesso speculavano sulla personalità del Padre, del Figlio e della Santissima Trinità, recando nel campo del diritto non solo ... gli stessi concetti e lo stesso spirito delle disquisizioni teologiche, ma persino .... le stesse forme esteriori e più singolari di trattazione" (Scritti Giuridici Varí, t. III, Torino, 1926, p. 472). Pela lei, ainda que seja essa, o Código Civil, mais uma vez se demonstra, - estão sempre, os homens, queiram ou não, consociados com Deus (Cícero, De Legibus, 1,23). 